\title{
PENGUJIAN KARAKTERISTIK FISIK JAGUNG BISI 2 UNTUK MENDESAIN MESIN PEMIPIL JAGUNG PORTABEL
}

\author{
Moh Fikri Pomalingo' ${ }^{1)}$, Agus Susanto Ginting ${ }^{2)}$, Sjahril Botutihe ${ }^{3)}$ \\ ${ }^{1,2,3}$ Program Studi Mesin dan Peralatan Pertanian, Politeknik Gorontalo \\ Email: fikri.pomalingo@ poligon.ac.id ${ }^{1)}$
}

\begin{abstract}
ABSTRAK
Jagung merupakan salah satu potensi lokal utama di Gorontalo. Komoditi ini dibudidayakan di lahan datar dan lahan miring. Desa Botuwombato merupakan salah satu desa yang penghasil jagung terbesar di Gorontalo. salah satu varietas jagung yang banyak dibudidayakan di Gorontalo adalah Jagung Bisi 2. Salah satu permasalahan yang dihadapi yaitu belum adanya data karakteristik fisik buah jagung. Penelitian ini bertujuan untuk menganalisis karakteristik fisik buah dan biji jagung Bisi 2 sehingga dapat merancang alat dan mesin pertanian yang baik dan tepat dalam pengoperasiannya. Alat yang direncakan adalah Tugal Jagung 3 in 1, yang dapat melakukan proses pelubangan tanah, pemasukan benih dan penimbunan dalam satu kegiatan. Mesin yang akan dirancang adalah mesin pemipil jagung portable, yang digerakkan oleh motor roda dua. Pemipil jagung terdiri dari dua poros pipil, yang dimensinya ditentukan berdasarkan diameter tongkol jagung. Pengukuran massa jagung dilakukan dengan menggunakan timbagan analitik. Massa yang diukur berupa berat buah, biji, dan tongkol. Pengukuran dimensi menggunakan jangka sorong. Buah Jagung (biji dan tongkol) dan tongkol jagung diukur pada bagian ujung, tengah dan pangkal. Biji jagung diukur berdasarkan panjang, lebar dan tebal. Hasil penelitian menunjukkan bahwa rerata massa jagung mencapai 108.6 g. Berat rerata biji jagung yang berada pada ujung, tengah dan pangkal secara berurutan mencapai $19.4 \mathrm{~g}, 22.2 \mathrm{~g}$, dan $24.2 \mathrm{~g}$. Hasil penelitian juga membuktikan bahwa dimensi biji jagung terbesar berada pada pangkal buah, sedangkan diameter tongkol terkecil berada pada ujung tongkol dengan nilai $19.4 \mathrm{~mm}$.
\end{abstract}

Kata Kunci: jagung, bisi 2, karakteristik fisik, Gorontalo, jangka sorong

ABSTRACT

Corn is one of main potentials plant in Gorontalo. This commodity is cultivated on flat land and sloping land. Botuwombato is one of the biggest corn-producing villages in Gorontalo. One of the corn varieties that are widely cultivated in Gorontalo is Bisi 2. One of the problems faced is the lack of data on the Physical Properties of corn. This study aims to analyze the physical properties of Bisi 2 corn and seeds for design tools and machines of agriculture that are good and appropriate in their operation. The equipment is 3 in 1, which can carry out the process of land punching, seed entry and stockpiling in one activity. The machine is a portable corn sheller machine, which is driven by motocycle. Corn sheller consists of two sheller shafts, whose dimensions are determined based on the diameter of the corn cobs. Corn mass measurements were carried out using an analytical baggage. The measured mass is the weight of fruit, seeds, and cob. Dimension measurement uses calipers. Corn fruit (seeds and cobs) and corn cobs are measured at the end, center and base. Corn seeds are measured based on length, width and thickness. Corn mass measurements were carried out using analytical weigher and dimensional measurements using caliper. The results showed mass of corn reached $108.6 \mathrm{~g}$. The average weight of corn seeds at the center, middle and base respectively reached $19.4 \mathrm{~g}, 22.2 \mathrm{~g}$, and $24.2 \mathrm{~g}$. The results also proved that the dimensions of the largest corn seeds were at the base of the corn, while the diameter of the small cob was at the tip of the ear with a value of $19.4 \mathrm{~mm}$.

Keywords: corn, bisi 2, physical properties, Gorontalo, caliper

\section{PENDAHULUAN}

Gorontalo merupakan salah satu daerah penghasil jagung terbesar di Indonesia. Daerah ini bahkan memiliki semboyan daerah jagung. Berdasarkan laporan dari dinas Pertanian, Tanaman Pangan dan Hortikutura tahun 2015, luas panen tanaman jagung mencapai 129.131 ha, dengan produksi mencapai 643.512 ton. Penanaman jagung di Gorontalo dilakukan pada lahan datar dan lahan miring.

Salah satu permasalahan di Gorontalo yaitu belum adanya data karakteristik fisik dari setiap varietas jagung yang dibudidayakan di Gorontalo. Pada umumnya data-data jagung hanya berkisar pada produktivitas, luas tanam, dan umur jagung, bahkan pada kemasan dari benih jagung yang dijual dipasaran, tidak mencantumkan data karakteristik fisik secara spesifik. 
Data karakterisitik fisik bahan pertanian khususnya jagung sangat bermanfaat bagi peneliti. Beberapa manfaat dari data tersebut yaitu 1) untuk perancangan alat dan mesin pertanian (Sinaga, 2016), 2) untuk menganalisis, mengevaluasi dan mempertahankan kualitas produk (Mohsenin, 1986) dan untuk digunakan dalam memprediksi produktivitas panen suatu bahan pertanian.

Berdasarkan hasil penelusuran jurnal yang dilakukan oleh penulis, penelitian yang berhubungan dengan karakterisitik fisik bahan pertanian telah banyak dilakukan, diantaranya; karaktiristik fisik biji macadamia (Braga et al., 1999), walnut atau biji kenari (Koyuncu et al., 2004), biji pinus (Ozguven dan Vursavus, 2005; Carcel et al., 2012), kacang pistachio (kashaninejad et al., 2006), biji jarak pagar (Karaj dan Muller, 2010) hazelnut atau kemiri dari Italia (Delprete dan Sesana, 2014) dan Biji Jagung (Yu et al., 2015).

Hasil penelitian Ekowati dan Nasir (2011) terhadap jagung Bisi 2 yang ditanam pada lahan pasir menyebutkan bahwa panjang tongkol jagung mencapai $14.18 \mathrm{~cm}$ dan diameter tongkol sebesar $3.09 \mathrm{~cm}$. Perkembangan biji jagung dipengaruhi oleh beberapa faktor, salah satunya yaitu pemberian Pyraclostrobin. Pyraclostrobin yaitu fungisida dari kelompok strobilurin yang dapat melindungi tanaman dari jamur (Asputri et al., 2013). Penelitian ini bertujuan untuk meneliti karakterisitik buah jagung sebagai upaya untuk perancangan mesin pemipil jagung portable. Jagung yang akan digunakan dalam penelitian ini adalah varietas bisi 2 .

\section{METODE PENELITIAN}

\subsection{Alat dan Bahan}

Peralatan yang digunakan dalam penelitian ini yaitu jangka sorong dengan ketelitian $0.05 \mathrm{~mm}$, alat tulis, kamera, timbangan maksimal pengukuran 200gr, mistar, dan terpal.

Bahan yang digunakan dalam penelitian ini adalah Jagung bisi 2 dan kertas.

\subsection{Metode Penelitian}

Jagung Bisi 2 diambil dari desa Botuwombato, kecamatan Kwandang, kabupaten Gorontalo Utara. Pengambilan sampel varietas Bisi 2, karena varietas ini banyak dibudidayakan di Gorontalo. Pemilihan desa Botuwombato, karena desa ini merupakan salah satu desa penghasil jagung terbesar di Gorontalo dengan rerata hasil panen sekitar 7-9 ton/ha.

Pengukuran karakteristik fisik hasil pertanian didahului dengan penentuan jumlah sampel. Dalam penelitian biji cemara Ozguven dan Vursavus (2005) menggunakan 100 biji yang diambil secara acak dan pengukurannya menggunakan jangka sorong. Pada pengukuran biji kenari Koyuncu et al (2004) menggunakan 60 biji yang diambil secara acak. Untuk pengukuran biji cemara digunakan 50 biji yang diambil secara acak (Carcel et al., 2012) sedangkan pengukuran biji kacang pistachio Kashaninejad et al. (2006) menggunakan 100 biji yang diambil secara acak.

Dalam penelitian ini, penulis mengambil 30 sampel buah jagung bisi 2 secara acak. Seluruh buah jagung selanjutnya ditimbang dalam keadaan belum dipipil, terpipil dan perbutir jagung. Jagung perbutir diambil dari bagian ujung, tengah dan pangkal jagung (Yu et al. 2015). Sampel jagung juga akan diukur dimensinya dengan menggunakan jangka sorong. Berdasarkan hasil penelitian Sinaga et al. (2016) pada buah kemiri, tiga dimensi utama yang perlu diambil dalam pengukuran bahan pertanian yaitu panjang, lebar dan tebal. Pada biji jagung panjang diartikan jarak dari ujung buah ke pangkal biji yang berbentuk lancip, lebar berarti jarak antara sisi kiri ke sisi kanan biji jagung, dan tebal berarti ketebalan jagung.

Hasil pengukuran karakteristik fisik buah jagung, selanjutnya diolah dengan menggunakan analisis statistik Deskriptif. Statistik deskriptif ialah statistika yang mendiskripsikan atau menggambarkan tentang data yang disajikan dalam bentuk tabel, diagram, pengukuran tendensi sentra(rata-rata hitung, rata-rata ukur, dan rata-rata harmonik), pengukuran penempatan (median, kuartil, desil, dan persentil), pengukuran penyimpanan (range, rentangan kuartil, rentangan semi antar kuartil, simpangan rata-rata, simpangan baku, varians, koefisien varian, dan angka baku), angka indeks serta mencari kuatnya hubungan dua variabel, melakukan peramalan (prediksi) dengan menggunakan analisis regresi linier, membuat perbandingan (komparatif). Hasil analisis selanjutnya dilaporkan dalam bentuk jurnal dan laporan akhir pada skema Penelitian Dosen Pemula (PDP) dari Kementrian Riset dan Teknologi.

\section{HASIL DAN PEMBAHASAN}

\subsection{Buah Jagung}

Jagung Bisi 2 merupakan salah satu varietas yang banyak dibudidayakan oleh petani. Langkah pertama yang dilakukan sebelum melakukan pengukuran adalah memberi tanda pada sampel yang akan diukur seperti yang ditampikan pada Gambar 1 . Varietas ini dianggap tahan hama, penyakit dan cocok dengan kondisi tanah di Gorontalo khususnya di desa Botuwombato. Hasil penelitian menunjukkan bahwa rerata berat buah jagung kupas sekitar $134.6 \mathrm{~g}$ dengan kadar air 19\% bb. Dari nilai tersebut, dilakukan pemipilan jagung pada setiap sampel. Hasil pengukuran rerata berat jagung terpipil mencapai 108.6 g. Hasil Pengukuran massa biji jagung terpipil ditampilkan pada Gambar 2. 


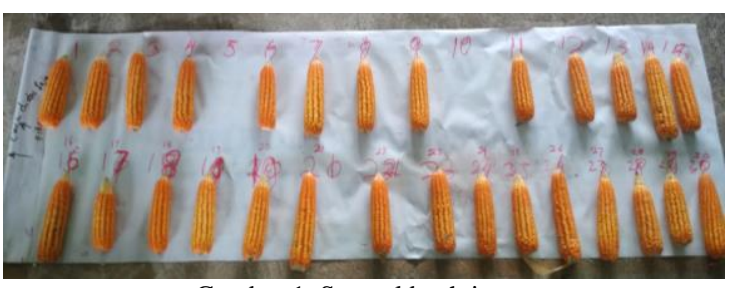

Gambar 1. Sampel buah jagung

Selain pengambilan data yang berkaitan dengan berat buah, peneliti juga mengambil data yang berkaitan dengan kondisi biji jagung yang menempel pada tongkol. Data hasil perhitungan jumlah baris dan row ditampilkan pada Tabel 1 . Jumlah baris berarti susunan biji jagung yang posisinya melingkari tongkol jagung, sedangkan row adalah jumlah jagung yang posisinya berada pada pangkal hingga ujung buah jagung.

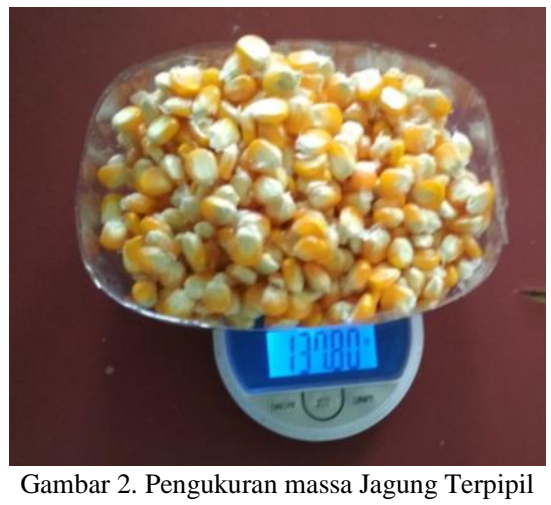

Tabel 1 menampilkan bahwa jumlah biji terbanyak dalam satu baris yaitu 16 biji yang ditunjukkan pada sampel 10. Jumlah baris terkecil diperlihatkan pada sampel 26 dengan 8 biji. Dalam penentuan jumlah biji pada row, sampel yang memiliki biji terbanyak yaitu sampel 21 dengan jumlah biji dalam satu row sebanyak 45 biji. Jumlah ini membuktikan bahwa semakin banyak biji dalam satu row, maka semakin panjang tongkol jagung. Dari pengamatan yang dilakukan juga, jumlah biji minimum dari saru row buah jagung mencapai 28 (Sampel 25).

Hasil pengamatan juga menjelaskan, bahwa semakin besar diameter tongkol jagung, maka semakin besar jumlah biji jagung dalam satu baris. Jumlah biji jagung pada umumnya mengikuti ukuran tongkol, sehingga sering ditemukan jagung yang pendek namun jumlah bijinya banyak. Sebaliknya sering ditemukan jagung dengan diameter kecil namun jumlah bijinya banyak. Kedua sampel jagung tersebut tergantung pada bentuk buah, karena sering ditemukan buah yang panjang diameternya kecil, sedangkan buah yang pendek diameternya besar.

Tabel 1. Hasil Perhitungan Baris dan Row Jagung

\begin{tabular}{ccc}
\hline \multirow{2}{*}{ Sampel } & \multicolumn{2}{c}{ Posisi } \\
\cline { 2 - 3 } & Baris & Row \\
\hline
\end{tabular}

\begin{tabular}{|c|c|c|}
\hline 2 & 12 & 38 \\
\hline 3 & 12 & 37 \\
\hline 4 & 10 & 40 \\
\hline 5 & 12 & 35 \\
\hline 6 & 10 & 33 \\
\hline 7 & 10 & 40 \\
\hline 8 & 10 & 39 \\
\hline 9 & 12 & 41 \\
\hline 10 & 16 & 29 \\
\hline 11 & 12 & 32 \\
\hline 12 & 10 & 34 \\
\hline 13 & 12 & 33 \\
\hline 14 & 12 & 33 \\
\hline 15 & 10 & 36 \\
\hline 16 & 10 & 37 \\
\hline 17 & 12 & 27 \\
\hline 18 & 10 & 34 \\
\hline 19 & 12 & 35 \\
\hline 20 & 12 & 35 \\
\hline 21 & 10 & 45 \\
\hline 22 & 12 & 33 \\
\hline 23 & 10 & 30 \\
\hline 24 & 12 & 32 \\
\hline 25 & 10 & 28 \\
\hline 26 & 8 & 44 \\
\hline 27 & 12 & 35 \\
\hline 28 & 10 & 31 \\
\hline 29 & 12 & 32 \\
\hline 30 & 14 & 36 \\
\hline erata & 11 & 35 \\
\hline
\end{tabular}

\section{2. $\quad$ Biji Jagung}

Pengamatan biji jagung secara langsung menggambarkan bahwa setiap posisi biji jagung pada buah jagung memiliki bentuk berbeda-beda. Dalam penentuan bentuk buah kebulatan didasarkan pada sifat isoperimetric suatu bola. Isoperimetrik adalah perbandingan antara volume bahan padat dengan volume lingkaran bola yang memiliki diameter yang sama dengan bahan (Mohsenin, 1986). Kebulatan juga sering ditentukan dengan perbandingan diameter rata-rata geometri (Carcel et al., 2012).

Biji jagung varietas bisi 2 memiliki ukuran yang lebih besar dari yang lainnya. Pengambilan sampel dilakukan dengan cara mencungkil biji pada buah bagian ujung, tengah dan pangkal. Pada umumnya masyarakat Gorontalo memiliki sebutan khusus untuk biji jagung. Biji jagung mutiara yaitu biji yang berbentuk seperti mutiara dengan tingkat 
kebulatan yang hampir sempurna. Pada buah jagung, biji ini berada pada bagian ujung. Gigi kuda merupakan bentuk biji yang menyerupai gigi kuda. Jenis ini biasanya berada pada bagian tengah dan pangkal buah.

Tabel 2 menjelaskan bahwa rerata massa biji terbesar berada pada bagian pangkal buah dengan nilai sebesar $0.32 \mathrm{~g}$. Biji dengan massa terkecil berada pada ujung buah dengan nilai $0.27 \mathrm{~g}$. Penimbangan biji jagung seperti yang ditampilkan pada Gambar 3. Data ini sangat dibutuhkan untuk memprediksi kapasitas panen dari jagung bisi 2. Dari tabel 2 juga dapat dikatakan bahwa semakin ke ujung buah maka massa biji jagung semakin kecil.

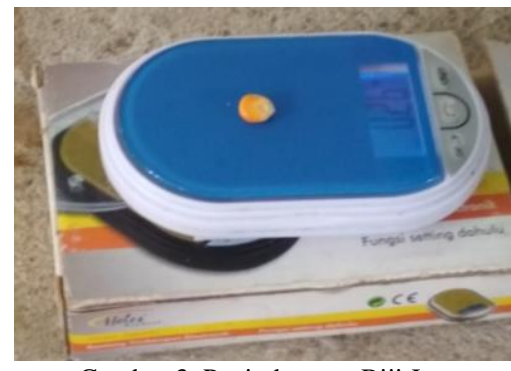

Gambar 3. Penimbangan Biji Jagung

Tabel 2. Rerata Massa Biji Jagung Berdasarkan Posisi Pada Buah

\begin{tabular}{cc} 
Bagian & Berat Biji $(\mathbf{g})$ \\
\hline Ujung & 0.27 \\
Tengah & 0.30 \\
Pangkal & 0.32 \\
\hline
\end{tabular}

Hasil pengukuran dimensi jagung (Gambar 4) sangat variatif. Tabel 3 menjelaskan bahwa rerata dimensi jagung terbesar berada pada bagian pangkal dengan dimensi panjang $9 \mathrm{~mm}$, lebar $9,2 \mathrm{~mm}$ dan tebal $4.4 \mathrm{~mm}$. Nilai ini sejalan dengan massa jagung yang dijelaskan pada tabel 2. Semikin berat biji jagung maka dimensinya semikin besar pula.

Tabel 3. Rerata Dimensi Biji Jagung

\begin{tabular}{cccc}
\hline \multirow{2}{*}{ Bagian } & \multicolumn{3}{c}{ Dimensi $(\mathbf{m m})$} \\
\cline { 2 - 4 } & Panjang & Lebar & Tebal \\
\hline Ujung & 8.8 & 8.1 & 4.2 \\
Tengah & 9.6 & 8.9 & 4 \\
Pangkal & 9 & 9.2 & 4.4 \\
\hline
\end{tabular}

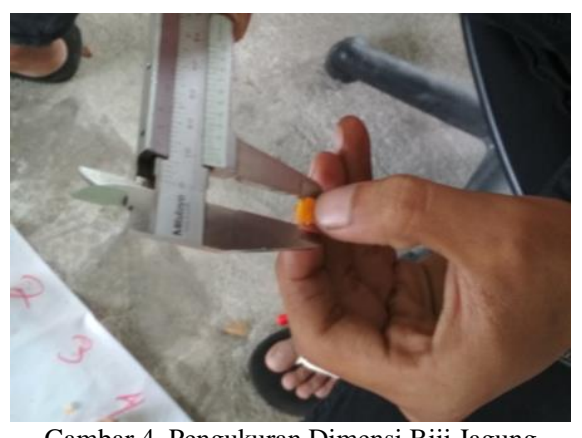

Gambar 4. Pengukuran Dimensi Biji Jagung
Pada Tabel 3 juga dapat dilihat adanya perbedaan dimensi pada biji bagian tengah buah. Rerata ukuran panjangnya lebih besar dari biji yang berada pada bagian pangkal. Hal ini dikarenakan biji bagian tengah buah lebih tipis sehingga memungkinkan perkembangan biji menjadi lebih panjang dan lebar.

\subsection{Tongkol}

Diameter tongkol sangat bagus untuk dijadikan dasar dalam perancangan ruang pemipil pada mesin pemipil jagung. Berdasarkan hasil pengukuran diameter tongkol jagung yang ditampilkan pada Tabel 4, terlihat bahwa rerata diameter tongkol jagung tertinggi terdapat pada bagian pangkal dengan ukuran $24.2 \mathrm{~mm}$ (gambar 5). Diameter jagung ini sangat sesuai dengan bentuk buah jagung yang semakin kebagian ujung buah diamternya semakin kecil. Pada pengukuran tongkol juga diperoleh berat tongkol jagung mencapai $23.1 \mathrm{~g}$ dengan kadar air $19 \%$ bb.

Tabel 4. Diameter Tongko

\begin{tabular}{ccc}
\hline Bagian & Dimensi $(\mathbf{m m})$ & Berat $(\mathbf{k g})$ \\
\hline Ujung & 19.4 & \\
Tengah & 22.2 & 23.1 \\
Pangkal & 24.2 & \\
\hline
\end{tabular}

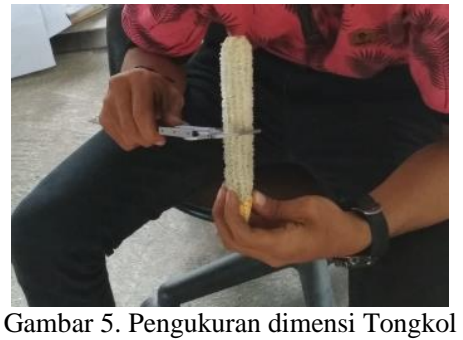

Dalam perancangan ruang pemipil, jarak antara poros pemipil dan dinding ruang pemipil ditentukan pada diameter terkecil dari bagian tongkol jagung. Tabel 4 menunjukkan bahwa ujung tongkol merupakan diameter terkecil dengan nilai $19.4 \mathrm{~mm}$. Nilai inilah yang dijadikan sebagai ruang kosong untuk penempatan buah jagung agar bisa terpipil dengan baik. Ruang pemipil jagung akan dirancang menggunakan material besi dan karet. Penggunaan karet bertujuan untuk mengurangi biji jagung yang rusak pada saat pemipilan. Ruang pemipil terdisi dari poros pemipil dan penutup yang statis. Jarak keduanya akan dirancang minimal $19.4 \mathrm{~mm}$. Desain ruang pemipilan dan desain mesin jagung portabel ditampilkan pada Gambar 6 dan 7. 


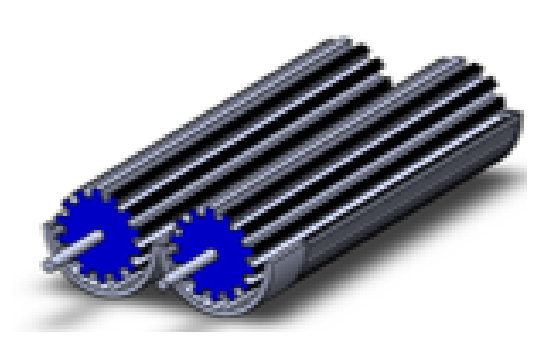

Gambar 6. Desain Ruang pemipil

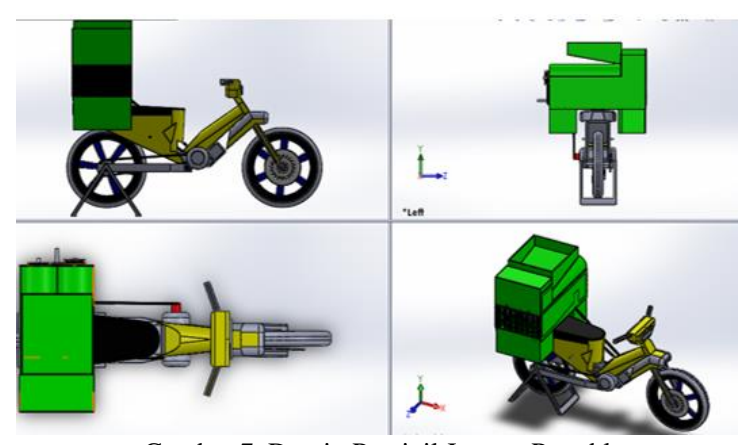

Gambar 7. Desain Pemipil Jagung Portable

\section{KESIMPULAN}

Dari hasil penelitian yang telah dilakukan, dapat disimpulkan bahwa:

1. Massa biji jagung terbesar berada pada bagian pangkal buah, sehingga semakin kearah ujung buah, massa biji jagung akan lebih kecil.

2. Dimensi buah jagung terbesar berada pada bagian pangkal buah jagung.

3. Diameter tongkol jagung terkecil berada pada bagian ujung buah, sehingga untuk jarak poros pemipil dan dinding pemipil disesuaikan dengan diameter ujung tongkol sebesar $19.4 \mathrm{~mm}$.

\section{UCAPAN TERIMA KASIH}

Ucapan terima kasih peneliti sampaikan kepada Kementrian Riset dan Teknologi Republik Indonesia yang telah memberikan dana penelitian melalui skema Penelitian Dosen Pemula (PDP) 2018. Ini merupakan jurnal kedua yang diterbitkan oleh penulis melalui PDP. Semoga dapat bermanfaat bagi bangsa Indonesia khususnya peneliti dan dosen yang akan meneliti tentang jagung Bisi 2.

\section{DAFTAR PUSTAKA}

Asputri, N.U., Aini, L.Q., \& Abadi, A.L. (2013). Pengaruh Aplikasi Pyraclostrobin Terhadap Serangan Penyeban Penyakit Bulai Pada Lima Varietas Jagung (Zea mays). Jurnal HPT, 1(3), 77-84

Braga, G.C., Couto, S.M., Hara, T., \& Neto, J.T.P.A. (1999). Mechanical behaviour of macadamia nut under compression loading. Journal of Agricultural Engineering, 72: 239-245.
Carcel, L.M., Bon, J., Acuna, L., Nevares, I., Alamo, M., \& Crespo, R. (2012). Moisture dependence on mechanical properties of pine nuts from pinus pinea L. Journal of Food Engineering, 110: 294-297.

Delprete, C., \& Sesana, R. (2014). Mechanical characterization of kernel and shell of hazelnut: Proposal of an experimental procedure. Journal of Food Engineering, 124: 28-34.

Ekowati, D., \& Nasir, M. (2011). Pertumbuhan Tanaman Jagung (Zea mays L.) Varietas Bisi 2 Pada Pasir Reject dan Pasir Asli di Pantai Trisik Kulonprogo. Jurnal Manusia dan Lingkungan, 18(3), 220-231.

Karaj, S., \& Muller, J. (2010). Determination of physical, mechanical and chemical properties of seeds and kernels of Jatropha curcas L. Industrial crops and products. 129-138.

Kashaninejad, M., Mortazavi, A., Safekordi, A., \& Tabil, L.G. (2006). Some physical properties of pistachio (Pistacia vera L.) nut and its kernel. Journal of Food Engineering, 72: 3038.

Koyuncu, M.A, Ekinci, K., \& Savran, E. (2004). Cracking characteristic of walnut. Journal of Biosystem Engineering. 87: 305-311.

Mohsenin, N.N. (1986). Physical properties of plant and animal materials. Structure, physical characteristics and mechanical properties. 2nd Revised and Updated Ed. Gordon and Breach Science Publishers. New York.

Ozguven, F., \& Vursavus, K. (2005). Some physical, mechanical and aerodynamic properties of pine (pinus pinea) nuts. Journal of Food Engineering. 68: 191-196.

Sinaga, R., Desrial, \& Wulandani, D. (2016). Karakterisitik Fisik dan Mekanik Kemiri (Aleurites moluccana Wild.). Jurnal Keteknikan Pertanian, 4(1), 97-106.

Yu, Y., Fu, H., \& Yu, J. (2015). DEM-Based Simulation of The Corn Threshing Process. Advenced Powder Technology. J. apt. 2015.07.015. 